\title{
Poplar woody root proteome during the transition dormancy-active growth
}

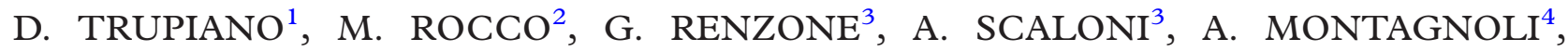 \\ M. TERZAGHI ${ }^{4}$, A. DI IORIO ${ }^{4}$, D. CHIATANTE ${ }^{4}, \&$ G.S. SCIPPA ${ }^{1}$
}

\begin{abstract}
${ }^{1}$ Dipartimento di Bioscienze e Territorio, University of Molise, 86090 Pesche, IS, Italy, ${ }^{2}$ Dipartimento Scienze e Tecnologie, University of Sannio, 82100 Benevento, Italy, ${ }^{3}$ Proteomics and Mass Spectrometry Laboratory, ISPAAM, National Research Council, 80147 Napoli, Italy and ${ }^{4}$ Dipartimento di Biotecnologie e Scienze della Vita, University of Insubria, 21100 Varese, Italy
\end{abstract}

\begin{abstract}
Woody plants living in temperate climates finely regulate their growth and development in relation to seasonal changes; their transition from vegetative to dormancy phase represents an adaptation to their environment. Events occurring in the shoot during onset/release from dormancy have been largely investigated, whereas in woody roots they remain completely unknown. In recent years, we have been interested in understanding the molecular and physiological events occurring in poplar woody root during release from dormancy. Here, we propose the results of a comparative analysis of the proteome of poplar woody root sampled at different time points: $\mathrm{T}_{0}$ (dormancy condition), $\mathrm{T}_{1}$ (release from dormancy), and $\mathrm{T}_{2}$ (full vegetative condition). This study identified proteins that may be involved in the long-term survival of a dormant root or landmarking a specific time point.
\end{abstract}

Keywords: Active growth-dormancy cycle, growth seasonal changes, Populus nigra, root proteome, woody root

\section{Introduction}

Temperate perennial woody plants use different environmental signals, i.e. light and temperature, to coordinate their growth and development in relation to seasonal changes. The capacity to modulate the phase shift from growth to dormancy is a basic adaptation of temperate perennial plants to their environment (Jansson et al. 2010; Desotgiu et al. 2012; Vitale et al. 2012). Indeed, the transition of meristems into and out of dormant bud is crucial for plant growth and survival (Furukawa et al. 2011).

Physiological and molecular changes occurring during dormancy induction and break have been mainly investigated in the shoots of several woody plants (Arora et al. 2003, Ruttink et al. 2007; Campoya et al. 2011; Terzoli et al. 2011), whereas the effects of seasonal changes on the root functions and activities have not been well characterized yet. For example, it is well established that photoperiod and temperature are the environmental signals that trigger the transitions between rapid growth and dormancy in the shoot of woody plants (Welling et al. 2002). Despite the recognized importance of the aboveground parts of trees, shrubs, and forests, roots have been poorly investigated (Long et al. 2011; Rewald et al. 2011; Delgado et al. 2012; Ow \& Sim 2012; Verma et al. 2012), and very few studies have been interested on the variety of internal (e.g., genotype of plant species) and external (e.g., light, temperature, precipitation, and soil properties) factors that coordinate root dynamics (Abbasi et al. 2011; Palove-Balang \&Mistrik 2011; Zhang et al. 2011) in relation to seasonal changes (Chiatante et al. 2005; Montagnoli et al. 2012a, 2012b; Zhang et al. 2012).

Since poplar is the first forest tree the genome of which has been determined (Tuskan et al. 2006), it has become a pivotal model for studies related to different aspects of growth and dormancy in woody plants (Durand et al. 2011; Bonadei et al. 2012). In previous studies, we investigated the effects of bending stress on the woody roots of poplar (Populus nigra) along a three-point time course that, based on 
shoot phenological observations, was proposed to correspond to dormancy, beginning of vegetative growth, and active growth (Trupiano et al. 2012a, $2012 b, 2013 b)$. Preliminary insights were also obtained on the molecular and physiological events occurring in poplar root during the transition from dormancy to active growth (Trupiano et al. 2013b). To further investigate molecular factors regulating the root functions, which may play important roles in the long-term survival of dormant structures, we reanalyzed the proteome of poplar woody root along the three time points. In this study, we present data referring to proteins remaining unchanged during the whole time course, together with the expression trend of the most significant proteins landmarking the dormancy, the beginning of vegetative growth, and the active growth.

\section{Materials and methods}

\section{Plant material}

The seedlings of one-year-old Populus nigra were grown in a mixture of soil, peat, and pumice under controlled water regime, natural photoperiod, and temperature (mean annual temperature of $12-13^{\circ} \mathrm{C}$ ) in a greenhouse. Taproots were harvested after 12 (February; $\mathrm{T}_{0}$; dormancy), 13 (March; $\mathrm{T}_{1}$; beginning of the vegetative growth), and 14 (April; $\mathrm{T}_{2}$; active growth) months of plant development; sections between 10 and $25 \mathrm{~cm}$ were randomly sampled and used for proteomic profiling. Three biological replicates were sampled for each condition.

\section{Protein extraction, 2D gel electrophoresis, gel scanning and analysis}

Total proteins were extracted according to the phenol protocol (Mihr \& Braun 2003) with minor modifications, as reported in Scippa et al. (2008), and separated by $2 \mathrm{D}$ gel electrophoresis (2-DE), as described by Trupiano et al. (2012a). 2-DE gels (in technical triplicate for each sample) were scanned using a GS-800 calibrated densitometer (Bio-Rad, Hercules, CA, USA); corresponding images were analyzed by the PDQuest software (Bio-Rad, Hercules, CA, USA). Spot detection and matching between gels were done automatically, followed by manual verification. Protein spots were annotated only if detectable in all gels. After normalization of the spot densities against the whole-gel densities, the percentage volume of each spot was averaged for three different replicates of each biological sample, and statistical Student's $t$-test analysis $(p<0.01)$ was carried out to find out significant changes in proteomic profiles between the samples. A twofold change in normalized spot densities was considered as indicative of a differential expression. Furthermore, to identify specific time-related protein markers, analysis of variance (ANOVA $-p<0.05$ ) was carried out.

\section{In-gel digestion, mass spectrometry and protein identification}

Spots were manually excised from the gels, triturated, and washed with water. Proteins were in-gel reduced, S-alkylated, and digested with trypsin as previously reported (Ialicicco et al. 2012). Digest aliquots were removed and subjected to a desalting/ concentration step on ZipTipC18 (Millipore Corp., Bedford, MA, USA) using $5 \%$ formic acid $/ 50 \%$ acetonitrile as eluent before MALDI-TOF-MS and/ or nanoLC-ESI-LIT-MS/MS analysis. Resulting MS data were used for protein identification following the procedures already described in Trupiano et al. (2012a, 2013b).

\section{Results and discussion}

In our earlier papers (Trupiano et al. 2012a, 2013b), we analyzed the effect of bending on the proteomic profile of poplar roots by performing a differential study with respect to non-bent counterparts; this study was carried out on time-course basis by analyzing the tissues from plants under a dormancy $\left(T_{0}\right)$, beginning of vegetative growth $\left(T_{1}\right)$, and active growth $\left(\mathrm{T}_{2}\right)$ condition, which are represented here according to their corresponding shoot phenology (Figure 1). Data related to unbent roots were simply used as a background to be subtracted to the whole proteomic data-set of the bent counterparts, with the aim to identify specific elements associable with root bending. Interpretation of the differential results for unbent roots at the three time points was achieved later; this is the topic of the short communication reported here.

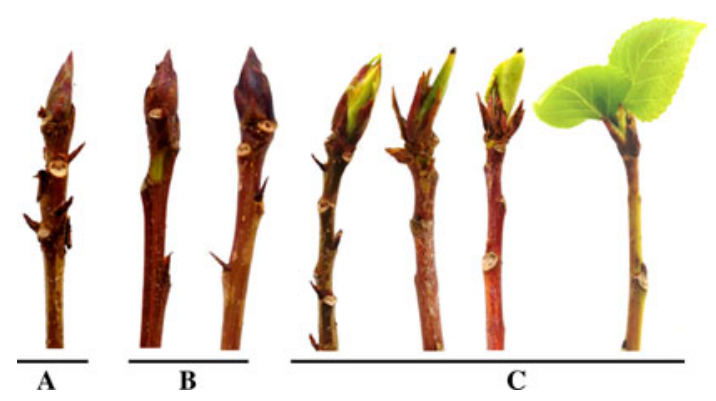

Figure 1. Populus nigra phenological stages assessment by bud development analysis: winter buds, stage A (February, $\mathrm{T}_{0}$ ); swelling buds, stage B (March, $\mathrm{T}_{1}$ ); flushing buds, stage C (April, $\mathrm{T}_{2}$ ). Bud development was quantified using six levels of morphology score $(0-6)$; minimal score $(0)$ was given to the winter bud and maximum score (6) to buds with a growing stem. 


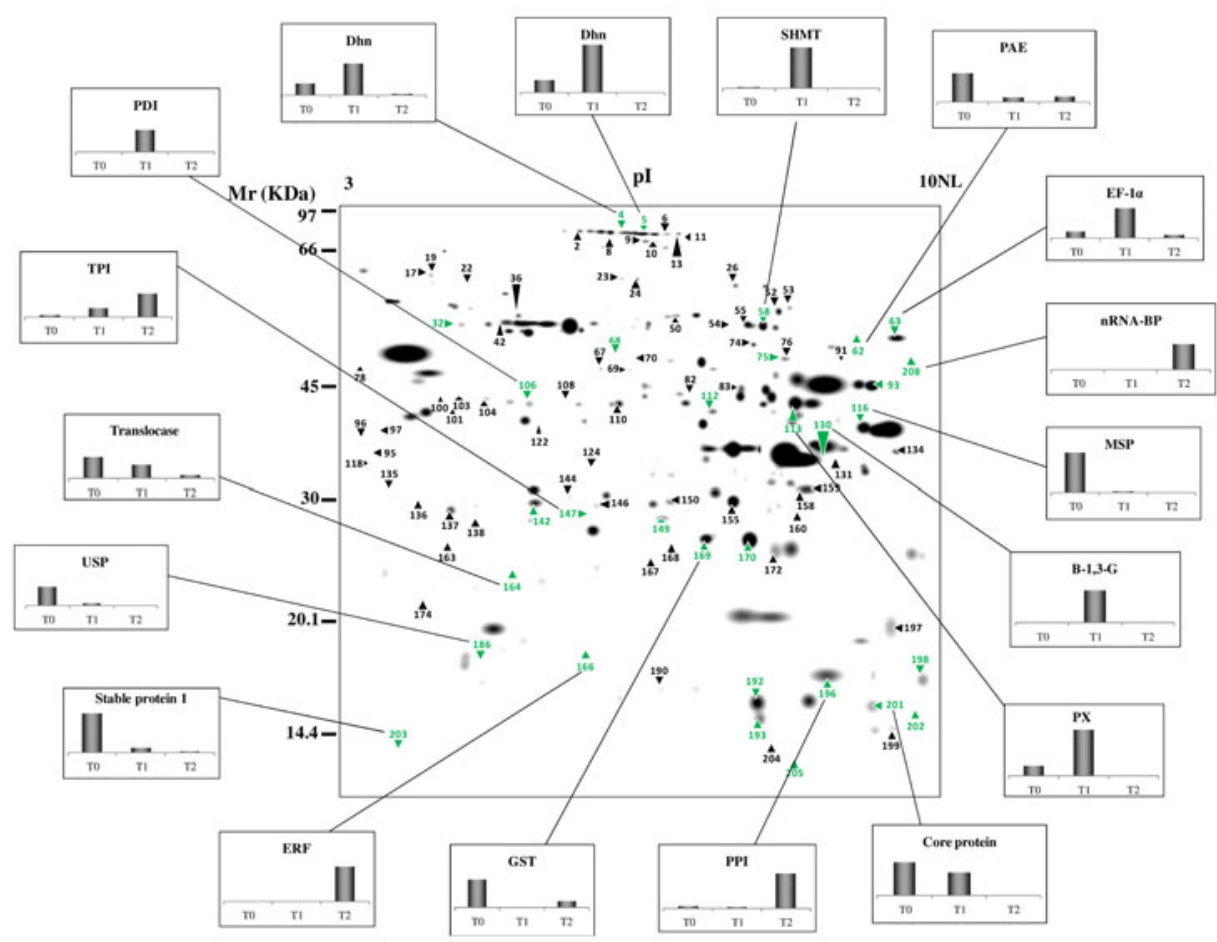

Figure 2. Two-dimensional proteome reference map of the woody poplar roots. The 31 proteins that were differentially expressed at a significant level (ANOVA $-p<0.05)$ during time course $\left(\mathrm{T}_{0}, \mathrm{~T}_{1}\right.$, and $\left.\mathrm{T}_{2}\right)$ are numbered in green. The expression trends of the main identified time-related protein markers are shown by histograms. The 63 constant proteins are numbered in black. $\beta-1,3-\mathrm{G}, \beta-1,3$-glucanase; Dhn, putative dehydrin; EF-1 $\alpha$, elongation factor $1 \alpha$; ERF, ethylene responsive factor; GST, glutathione- $S$-transferase; MSP, major storage protein; nRNA-BP, nuclear RNA-binding protein; PAE, pectin acetyltransferase; PDI, protein disulfide isomerase; PPI, peptidyl-prolyl cistrans isomerase; PX, peroxidase; SHMT, serine hydroxymethyltransferase; TPI, triosephosphate isomerase; USP, universal stress protein.

Proteomic analysis of the unbent woody root according to a time-course basis $\left(\mathrm{T}_{0}, \mathrm{~T}_{1}\right.$, and $\left.\mathrm{T}_{2}\right)$ revealed the presence of 63 constant proteins and of 31 differentially represented spots (Figure 2). As shown in Figure 3, beside proteins that regulate the main energy production pathways (glycolysis, tricarboxylic acid cycle, pentose-phosphate shunt, gluconeogenesis, and ATP synthesis), constant components included (i) molecular species involved in lipid mobilization, beta-oxidation and synthesis, such as patatin-like protein 3 (spot 23), electron transfer flavoprotein-ubiquinone oxidoreductase (spot 124), acetyl-CoA acetyltransferase (spot 67), and two aconitase isoforms (spots 11 and 13),

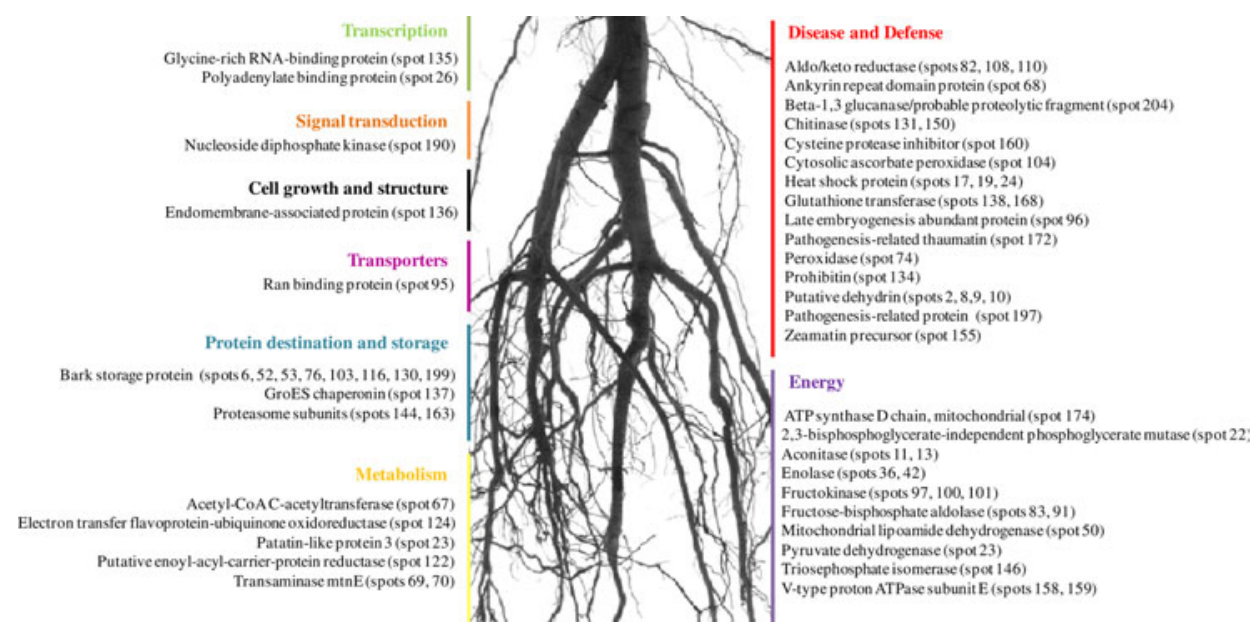

Figure 3. Constantly expressed protein spots characterizing woody taproots at $T_{0}, T_{1}$, and $T_{2}$. Spot number and protein name of constantly expressed protein spots along the time course $\left(\mathrm{T}_{0}, \mathrm{~T}_{1}\right.$, and $\left.\mathrm{T}_{2}\right)$ are listed on the basis of their functional classification provided according to Bevan et al. (1998). 
already described as involved in cambial reactivation (Druart et al. 2007; Park et al. 2008); (ii) a membrane-associated putative enoyl-acyl carrier protein reductase (spot 122) belonging to the fatty acid synthase complex machinery; (iii) an endomembrane-associated protein (spot 136), which is induced in early spring to maintain plasma membrane permeability (Schrader et al. 2004; Massengo-Tiassé \& Cronan 2009); (iv) mitochondrial lipoamide dehydrogenase (spot 50) and pyruvate dehydrogenase (spot 23), which are partners in the pyruvate dehydrogenase complex, thus linking cytosolic glycolytic metabolism with the tricarboxylic acid cycle. No significant changes were also observed for (i) two isoforms of transaminase mtnE (spots 69 and 70) that is involved in Met recycle thus maintaining intracellular Met and $S$-adenosylmethionine (AdoMet) levels for proper biosynthesis of ethylene and polyamines (Miyazaki \& Yang 1987), which are essential plant regulators of response to abiotic stress (Gill \& Tuteja 2010) and cell division in the cambial meristems (Papadakis \& Roubelakis-Angelakis 2005; Love et al. 2009); (ii) a ran-binding protein (spot 95) and prohibitin (spot 134), which are both involved in the regulation of cell division and development (Dasso 2001; Ahn et al. 2006; Van Aken et al. 2007, 2010; Love et al. 2009), ethylene signaling (Christians \& Larsen 2007), and oxidative stress (Ahn et al. 2006). In the latter context, ROS-scavenging enzymes, such as cystosolic ascorbate peroxidase (spot 104), aldoketoreductase (spots 82, 108, and 110 ), gluthatione- $S$-transferase (spots 138, 168, and 104), and peroxidase (spot 74), were also observed as constantly expressed. In particular, $\mathrm{H}_{2} \mathrm{O}_{2}$ is a signaling molecule involved in triggering dormancy transition into bud break (Prassinos et al. 2011). Constant expression of $\mathrm{H}_{2} \mathrm{O}_{2}$-scavenging enzymes may be required to reduce toxicity and to allow cambium activation (Mazzitelli et al. 2007). Finally, various cold-responsive factors eventually related to the protection of reactivating cambium (Druart et al. 2007) also presented unvarying expression overtime. They included pathogenesis-related thaumatin (spot 172), zeamatin precursor (spot 155), chitinase (spots 118,131 , and 150), cystein protease inhibitor (spot 160), late embryogenesis abundant protein (spot 96), glycine-rich RNA-binding protein (spot 135), heat shock protein (spots 17 and 19), dehydrin (spots 2, 8, 9 , and 10), proteasome $\alpha$ and $\beta$ subunits (spots 144 and 163), and GroES chaperonin (spot 137).

Conversely, 31 protein spots were found to be differentially represented in the unbent roots along the three-point time course (ANOVA $-p<0.05$ ). In this study, we focus on the expression trend of these deregulated proteins, with the aim to identify important time-related landmarks. At $\mathrm{T}_{0}$ (February), which is characterized by reduced temperature values $\left(-1.8\right.$ to $\left.11.1^{\circ} \mathrm{C}\right)$ and a related water deficit, spots corresponding to factors protecting cellular structures from cold and water stress showed augmented quantitative levels. In fact, low temperatures and water deficit may determine several cellular changes in woody plants, such as perturbations in membrane structure, protein denaturation, and increased levels of toxic solutes. All these changes in turn may have induced the over-expression of (i) stress-responsive proteins, such as glutathione- $S$-transferase (spot 169), stable protein 1 (spot 203), and universal stress protein (spot 186) (Wang et al. 2002); (ii) membrane protection and cell wall remodeling factors, such as translocase (spot 164), core protein (spot 201), and pectin-acetyl esterase (spot 62) (Uemura \& Steponkus 1999; Ermel et al. 2000; Follet-Gueye et al. 2000) (Figure 2). $\mathrm{T}_{0}$ was also characterized by the overexpression of a major storage protein (spot 116) (Figure 2). Storage proteins are important for $\mathrm{N}$ recycling from senescing leaves to bark and back to growing leaves in the spring (Gomez \& Faurobert 2002). In this context, it has been already reported that Populus accumulates storage proteins during autumn (Clausen \& Apel 1991), which are then used in spring to provide $\mathrm{N}$ and $\mathrm{C}$ for new growth (Wetzel et al. 1989).

$\mathrm{T}_{1}$ (March) resulted to be clearly marked by the increased levels of $\beta$-1,3-glucanase (spot 130) (Figure 2). The accumulation of this enzyme, which degrades callose (Ruonala et al. 2008; Levy \& Epel 2009; Rinne et al. 2011), has been already associated with the restoration of growth-promoting substances, the transport of molecular signals between cells, and the production of cryostabilizing sugars to maintain turgor in dehydrating cells (Kaplan \& Guy 2004) (Figure 2). At $\mathrm{T}_{1}$, with temperatures comprised in the $2-15^{\circ} \mathrm{C}$ range, the over-representation of stress/detoxification-related proteins, such as dehydrins (spots 4 and 5), ascorbate peroxidase (spot 142) and peroxidase (spot 113), may be required for the activation of ROS signaling pathways involved in root cambium reactivation (Yakovlev et al. 2008; Hanin et al. 2011). Factors involved in protein synthesis/folding, such as serine hydroxymethyltransferase (spot 58), elongation factor 1-alpha (spot 63), and protein disulfide isomerase (spot 106), also marked $\mathrm{T}_{1}$ for their increased representation; they may represent a further evidence of the molecular events preparing root to growth reactivation (Trupiano et al. 2013b) (Figure 2).

Enzymes involved in energy metabolism (triosephosphate isomerase; spot 147) and components playing key roles in post-translational control of RNAs (nuclear RNA-binding protein; spot 208) and protein folding (peptidyl-prolyl cis-trans isomerase; spot 196) marked $T_{2}$ (April) for their high representation, thus indicating the occurrence of 
processes related to active plant growth (Druart et al. 2007) (Figure 2). Indeed, an ethylene responsive protein factor (ERF; spot 166) also marked $\mathrm{T}_{2}$ (Figure 2). This protein is implicated in many plant physiological functions, such as cellular proliferation and lateral roots formation (Negi et al. 2008; Neri et al. 2011; Trupiano et al. 2013a).

In conclusion, the proteomic analysis presented here provided information on the molecular species and the metabolic pathways activated in the poplar roots as a result of seasonal changes. Although preliminary information on constant and timerelated protein markers was derived, our investigation was limited to a very short temporal gradient. Thus, additional studies of the entire growth cycle are required to fully understand the molecular mechanisms underlying active-dormant cycling of the tree roots. By confirming the quantitative changes described here for some proteins mentioned earlier, these studies will complete the picture resulting from investigations already done on stem cambial meristems and apical bud (Schrader et al. 2004; Druart et al. 2007; Rohde \& Bhalerao 2007; Park et al. 2008; Baba et al. 2011), which emphasized the complex network of interactions existing between environmental and internal factors.

\section{References}

Abbasi MK, Sharif S, Kazmi M, Sultan T, Aslam M. 2011. Isolation of plant growth promoting rhizobacteria from wheat rhizosphere and their effect on improving growth, yield and nutrient uptake of plants. Plant Biosyst 145: 159-168.

Ahn CS, Lee JH, Hwang AR, Kim WT, Pai HS. 2006. Prohibitin is involved in mitochondrial biogenesis in plants. Plant $\mathrm{J}$ 46: 658-667.

Arora R, Rowland LJ, Tanino K. 2003. Induction and release of bud dormancy in woody perennials: A science comes of age. HortScience 38: 911-921.

Baba K, Karlberg A, Schmidt J, Schrader J, Hvidsten TR, Bako L, Bhalerao RP. 2011. Activity-dormancy transition in the cambial meristem involves stage-specific modulation of auxin response in hybrid aspen. Proc Natl Acad Sci USA 108: 3418-3423.

Bevan M, Bancroft I, Bent E, Love K, Goodman H, Dean C, et al. 1998. Analysis of $1.9 \mathrm{Mb}$ contiguous sequence from chromosome 4 of Arabidopsis thaliana. Nature 391: 485-488.

Bonadei M, Zelasco S, Giorcelli A, Gennaro M, Calligari P, Quattrini E, et al. 2012. Transgene stability and agronomical performance of two transgenic Basta (R)-tolerant lines of Populus alba L. Plant Biosyst 146(1): 33-40.

Campoya JA, Ruiz D, Egea J. 2011. Seasonal progression of bud dormancy in apricot (Prunus armeniaca L.) in a Mediterranean climate: A single-node cutting approach. Plant Biosyst 145: 596-605.

Chiatante D, Di Iorio A, Scippa GS. 2005. Root responses of Quercus ilex L. seedlings to drought and fire. Plant Biosyst 139: 198-208.

Christians MJ, Larsen PB. 2007. Mutational loss of the prohibitin AtPHB3 results in an extreme constitutive ethylene response phenotype coupled with partial loss of ethylene-inducible gene expression in Arabidopsis seedlings. J Exp Bot 58: 2237-2248.
Clausen S, Apel K. 1991. Seasonal changes in the concentration of the major storage protein and its mRNA in xylem ray cells of poplar trees. Plant Mol Biol 17: 669-678.

Dasso M. 2001. Running on Ran: Nuclear transport and the mitotic spindle. Cell 104: 321-324.

Delgado JA, González-Garrido L, Martínez T. 2012. How deep must we dig? Sampling depth effects on root biomass assessments in Mediterranean riparian buffers. Plant Biosyst 146(2): 413-418.

Desotgiu R, Cascio C, Pollastrini M, Gerosa G, Marzuoli R, Bussotti F. 2012. Short and long term photosynthetic adjustments in sun and shade leaves of Fagus sylvatica L. investigated by fluorescence transient (FT) analysis. Plant Biosyst 146: 206-216.

Druart N, Johansson A, Baba K, Schrader J, Sjodin A, Bhalerao RR, et al. 2007. Environmental and hormonal regulation of the activity-dormancy cycle in the cambial meristem involves stage-specific modulation of transcriptional and metabolic networks. Plant J 50: 557-573.

Durand TC, Baillif P, Alberic P, Carpin S, Label P, Hausman JF, Morabito D. 2011. Cadmium and Zinc are differentially distributed in Populus tremula $\times$ P. alba exposed to metal excess. Plant Biosyst 145(2): 397-405.

Ermel FF, Follet-Gueye M, Cibert C, Vian B, Morvan C, Catesson A, Goldberg R. 2000. Differential localization of arabinan and galactan side-chains of rhamnogalacturonan $\mathrm{I}$ in cambial derivatives. Planta 210: 732-740.

Follet-Gueye ML, Ermel FF, Vian B, Catesson AM, Goldberg R. 2000. Pectin remodelling during cambial derivative differentiation. In: Savidge R, Barnett JR, Napier R, editors. Cell and molecular biology of wood formation. Oxford: BIOS Scientific. pp. 289-294.

Furukawa J, Kanazawa M, Satoh S. 2011. Dormancy-induced temporal up-regulation of root activity in calcium translocation to shoot in Populus maximowiczii. Plant Root 6: 10-18.

Gill S, Tuteja N. 2010. Reactive oxygen species and antioxidant machinery in abiotic stress tolerance in crop plants. Plant Physiol Biochem 48: 909-930.

Gomez L, Faurobert M. 2002. Contribution of vegetative storage proteins to seasonal nitrogen variations in the young shoots of peach trees (Prunus persica L. Batsch). J Exp Bot 53: 2431-2439.

Hanin M, Brini F, Fbel C, Toda Y, Takeda S, Masmoudi K. 2011. Plant dehydrins and stress tolerance: Versatile proteins for complex mechanisms. Plant Sign Behav 6: 1503-1505.

Ialicicco M, Viscosi V, Arena S, Scaloni A, Trupiano D, Rocco M, et al. 2012. Lens culinaris Medik. seed proteome: Analysis to identify specific markers. Plant Sci 197: 1-9.

Jansson S, Bhalerao RP, Groover AT. 2010. Genetics and genomics of populus. Series: Plant genetics and genomics: Crops and models. Vol. 8. New York: Springer. p. 368.

Kaplan F, Guy CL. 2004. $\beta$-Amylase induction and the protective role of maltose during temperature shock. Plant Physiol 135: 1674-1684.

Levy A, Epel BL. 2009. Cytology of the (1,3)- $\beta$-glucan (callose) in plasmodesmata and sieve plate pores. In: Bacic A, Fincher GB, Stone BA, editors. Chemistry, biochemistry, and biology of $(1,3)-\beta$-glucans and related polysaccharides. Burlington, MA: Elsevier. pp. 439-463.

Long F, Sunb HL, Liab SC. 2011. Influence of rocky slope gradient on root anchorage of Vitex negundo L. Plant Biosyst 145.

Love J, Bjorklund S, Vahala J, Hertzberg M, Kangasjarvi J, Sundberg B. 2009. Ethylene is an endogenous stimulator of cell division in the cambial meristem of Populus. Proc Natl Acad Sci USA 106: 5984-5989.

Massengo-Tiassé RP, Cronan JE. 2009. Diversity in enoyl-acyl carrier protein reductases. Cell Mol Life Sci 66: 1507-1517. 
Mazzitelli L, Hancock RD, Haupt S, Walker PG, Pont SDA, $\mathrm{McNicol} \mathrm{J}$, et al. 2007. Co-ordinated gene expression during phases of dormancy release in raspberry (Rubus idaeus L.) buds. J Exp Bot 58: 1035-1045.

Mihr C, Braun HP. 2003. Proteomics in plant biology. In: Conn P, editor. Handbook of proteomics. Totowa, NJ: Humana Press. pp. 409-416.

Miyazaki JH, Yang SF. 1987. The methionine salvage pathway in relation to ethylene and polyamine biosynthesis. Physiol Plantarum 69(2): 366-370.

Montagnoli A, Terzaghi M, Di Iorio A, Scippa GS, Chiatante D. 2012a. Fine-root seasonal pattern, production and turnover rate of European beech (Fagus sylvatica L.) stands in Italy Prealps: Possible implications of coppice conversion to high forest. Plant Biosyst 146: 1012-1022.

Montagnoli A, Terzaghi M, Di Iorio A, Scippa GS, Chiatante D. 2012 b. Fine-root morphological and growth traits in a Turkeyoak stand in relation to seasonal changes in soil moisture in the Southern Apennines, Italy. Ecol Res 27: 1015-1025.

Negi S, Ivanchenko MG, Muday GK. 2008. Ethylene regulates lateral root formation and auxin transport in Arabidopsis thaliana. Plant J 55: 175-187.

Neri D, Lee ON, Savini G, Kurokura T, Sugiyama N. 2011. Lateral root formation in the strawberry Fragaria $\times$ ananassa Duch. revealed by histone $\mathrm{H} 4$ in situ hybridization. Plant Biosyst 145(2): 406-410.

Ow LF, Sim EK. 2012. Detection of urban tree roots with the ground penetrating radar. Plant Biosyst 146: 288-297.

Palove-Balang P, Mistrik I. 2011. Title: Effect of aluminium on nitrogen assimilation in roots of Lotus japonicus. Plant Biosyst 145: 527-531.

Papadakis A, Roubelakis-Angelakis K. 2005. Polyamines inhibit NADPH oxidase-mediated superoxide generation and putrescine prevents programmed cell death induced by polyamine oxidase-generated hydrogen peroxide. Planta 220: $826-837$.

Park S, Keathley DE, Han KH. 2008. Transcriptional profiles of the annual growth cycle in Populus deltoides. Tree Physiol 28: $321-329$

Prassinos C, Rigasa S, Kizisa D, Vlahoub A, Hatzopoulosa P. 2011. Subtle proteome differences identified between postdormant vegetative and floral peach buds. J Proteomics 74: 607-619.

Rewald B, Leuschnera C, Wiesmanb Z, Ephrathc JE. 2011. Influence of salinity on root hydraulic properties of three olive varieties. Plant Biosyst 145(1): 12-22.

Rinne PLH, Welling A, Vahala J, Ripel L, Ruonala R, Kangasjarvi J, van der Schoot C. 2011. Chilling of dormant buds hyperinduces FLOWERING LOCUS $\mathrm{T}$ and recruits GAinducible 1,3-beta-glucanases to reopen signal conduits and release dormancy in Populus. Plant Cell 23: 130-146.

Rohde A, Bhalerao RP. 2007. Plant dormancy in the perennial context. Trends Plant Sci 12: 217-223.

Ruonala R, Rinne PLH, Kangasjarvi J, van der Schoot C. 2008. CENL1 expression in the rib meristem affects stem elongation and the transition to dormancy in Populus. Plant Cell 20: $59-74$.

Ruttink T, Arend M, Morreel K, Storme V, Rombauts S, Fromm J, et al. 2007. A molecular timetable for apical bud formation and dormancy induction in poplar. Plant Cell 19: 2370-2390.

Schrader J, Moyle R, Bhalerao R, Hertzberg M, Lundeberg J, Nilsson P, Bhalerao RP. 2004. Cambial meristem dormancy in trees involves extensive remodelling of the transcriptome. Plant J 40: 173-187.
Scippa GS, Trupiano D, Rocco M, Di Iorio A, Chiatante D. 2008. Unravelling the response of poplar (Populus nigra) roots to mechanical stress imposed by bending. Plant Biosyst 142: 401-413.

Terzoli S, Beritognolo I, Giovannelli A, Benelli C, Migliaccio F, Piconese S, et al. 2011. Expression of Aux/IAA genes during development of sylleptic and proleptic buds in white poplar. Plant Biosyst 145(2): 370-380.

Trupiano D, Di Iorio A, Montagnoli A, Lasserre B, Rocco M, Grosso A, et al. 2012b. Involvement of lignin and hormones in the response of woody poplar taproots to mechanical stress. Physiol Plantarum 146(1): 39-52.

Trupiano D, Renzoni G, Rocco M, Scaloni A, Viscosi V, Chiatante D, Scippa GS. 2012a. The proteome of Populus nigra woody root: Response to bending. Ann Bot 110(2): 415-432.

Trupiano D, Rocco M, Scaloni A, Renzoni G, Rossi M, Viscosi V, et al. 2013b. Temporal analysis of poplar woody root response to bending stress. Physiol Plantarum. doi: 10.1111/ppl.12072.

Trupiano D, Yordanov Y, Regan S, Meilan R, Tschaplinski T, Scippa GS, Busov V. 2013a. Identification, characterization of genes affecting adventitious root formation in Populus via activation tagging. Planta 238(2): 271-282.

Tuskan GA, Difazio S, Jansson S, Bohlmann J, Grigoriev I, Hellsten U, et al. 2006. The genome of black cottonwood, Populus trichocarpa (Torr. \& Gray). Science 313: 1596-1604.

Uemura M, Steponkus PL. 1999. Cold acclimation in plants: Relationship between lipid composition and the cryostability of the plasma membrane. J Plant Res 112: 245-254.

Van Aken O, Pecenkova T, Van De Cotte B, De Rycke R, Eeckhout D, Fromm H, et al. 2007. Mitochondrial type-I prohibitins of Arabidopsis thaliana are required for supporting proficient meristem development. Plant J 52: 850-864.

Van Aken O, Whelan J, Van Breusegem F. 2010. Prohibitins: Mitochondrial partners in development and stress response. Trends Plant Sci 15: 275-282.

Verma P, Mathur AK, Shanker K. 2012. Growth, alkaloid production, rol genes integration, bioreactor up-scaling and plant regeneration studies in hairy root lines of Catharanthus roseus. Plant Biosyst 146: 27-40.

Vitale L, Arena C, Virzo De Santo A. 2012. Seasonal changes in photosynthetic activity and photochemical efficiency of the Mediterranean shrub Phillyrea angustifolia L. Plant Biosyst 146 (2): 443-450.

Wang WX, Pelah D, Alergand T, Shoseyov O, Altman A. 2002. Characterization of SP1, a stress-responsive, boiling-soluble, homo-oligomeric protein from aspen. Plant Physiol 130: $865-875$.

Welling A, Moritz T, Palva ET, Junttila O. 2002. Independent activation of cold acclimation by low temperature and short photoperiod in hybrid aspen. Plant Physiol 129: 1633-1641.

Wetzel S, Demmers C, Greenwood JS. 1989. Seasonally fluctuating bark proteins are a potential form of nitrogen storage in three temperate hardwoods. Planta 178: 275-281.

Yakovlev IA, Asante DKA, Fossdal CG, Partanen J, Junttila O, Johnsen O. 2008. Dehydrins expression related to timing of bud burst in Norway spruce. Planta 228: 459-472.

Zhang J, Liu H, Zhao Q-Z, Du YX, Chang QX, Lu QL. 2011. Effects of ATP production on silicon uptake by roots of rice seedlings. Plant Biosyst 145: 866-872.

Zhang Y, Xuehong M, Zhichun Z. 2012. The influence of light conditions and interspecific competition on the root foraging traits and seedling growth of two tree species. Plant Biosyst 146 (1): $7-14$. 